\title{
Indicadores de desenvolvimento sustentáveis: uma análise comparativa das instituições formadas por agrupamentos territoriais de Santa Catarina - Brasil
}

O estudo foi realizado por meio de uma análise comparativa onde buscou entender quais pontos implicam na elevação dos indicadores de desenvolvimento sustentável. Como objetivo, a pesquisa visa demonstrar quais pontos devem ser fortalecidos oferecendo caminhos alternativos ao desenvolvimento dos indicadores. Como procedimento metodológico, adotamos uma análise documental das instituições no período de 2012 a 2014 evidenciando a dimensão sociocultural, econômica, política e ambiental. As principais constatações demonstram uma variação dos percentuais de desenvolvimento sustentável, bem como, formas de melhorar a classificação das instituições nos indicadores de sustentabilidade.

Palavras-chave: Sustentabilidade; Instituições; Indicadores de sustentabilidade.

\section{Sustainable development indicators: a comparative analysis of the institutions formed by territorial groups in Santa Catarina - Brazil}

The study was carried out through a comparative analysis where it sought to understand which points imply in raising the indicators of sustainable development. As an objective, the research aims to demonstrate which points should be strengthened by offering alternative paths to the development of the indicators. As a methodological procedure, we adopted a documentary analysis of the institutions from 2012 to 2014, highlighting the socio-cultural, economic, political and environmental dimension. The main findings demonstrate a variation in the percentages of sustainable development, as well as ways to improve the ranking of institutions in sustainability indicators.

Keywords: Sustainability; Institutions; Sustainability indicators.

Topic: Desenvolvimento, Sustentabilidade e Meio Ambiente Reviewed anonymously in the process of blind peer.
Received: 25/03/2021

Approved: 12/04/2021
Anderson Saccol Ferreira (it)

Universidade do Oeste de Santa Catarina, Brasil

http://lattes.cnpq.br/4850843904897537

http://orcid.org/0000-0002-6237-9912

anderson.ferreira@unoesc.edu.br
Referencing this:

FERREIRA, A. S.. Indicadores de desenvolvimento sustentáveis: uma análise comparativa das instituições formadas por agrupamentos territoriais de Santa Catarina - Brasil. Natural Resources, v.11, n.2, p.57-74, 2021. DOI:

http://doi.org/10.6008/CBPC22379290.2021.002.0008 
Indicadores de desenvolvimento sustentáveis: uma análise comparativa das instituições formadas por agrupamentos territoriais de Santa Catarina Brasil

\section{INTRODUÇÃO}

A pesquisa faz uma análise comparativa dos indicadores de desenvolvimento municipal sustentável, onde se tenta entender quais pontos do desenvolvimento implicam na elevação dos indicadores e quais fatores necessitam de maior atenção dos agrupamentos territoriais. O objetivo da pesquisa consiste em analisar os indicadores municipais de desenvolvimento sustentável e comparar os pontos positivos e negativos para gerar caminhos alternativos para o desenvolvimento sustentável.

Como procedimento metodológico adotado buscou-se analisar os indicadores de desenvolvimento sustentável municipal das instituições formadas pelos agrupamentos territoriais do estado de Santa Catarina entre o ano de 2012 e 2014, comparando suas similaridades e discrepâncias acerca de uma análise documental. As instituições foram agrupadas gerando um relatório onde foram analisados os três agrupamentos com maior e menor posicionamento no ranking de indicadores de desenvolvimento municipal sustentável.

As principais constatações do estudo indicam variações dos percentuais de desenvolvimento dos três primeiros e das três últimas instituições. Foram onde estão os maiores investimentos feitos e os que mais se desenvolveram no período da análise. Além desta parte introdutória, o artigo está dividido no referencial teórico que enfatiza os conceitos acerca de uma abordagem institucional dos agrupamentos territoriais conceituando o desenvolvimento sustentável. Em seguida, apresentam-se os procedimentos metodológicos e a análise dos resultados da pesquisa e por fim as considerações finais do estudo.

\section{REVISÃO TEÓRICA}

\section{Abordagem Institucional}

Os agrupamentos territoriais podem ser definidos como ato ou efeito de agrupar-se, com um propósito de desenvolvimento e crescimento da região onde eles se encontram buscando estratégias que interligam formando redes com um objetivo comum (FERREIRA, 2010). Permitem que os municípios executem projetos em conjunto, tanto na busca de recursos financeiros como assessorias no planejamento estratégico para seu desenvolvimento social, econômico e ambiental. Podem-se caracterizar os agrupamentos territoriais como instituições por serem organizações sociais que controlam o funcionamento da sociedade e consequentemente os indivíduos, compreendendo a natureza política e econômica da região (NORTH, 1990).

Segundo North (1990) "instituições são as regras do jogo em uma sociedade ou, mais formalmente, são os constrangimentos humanamente inventados que moldam a interação humana". Dessa forma, as instituições constituem redes de incentivo na interação social, de ordem política e econômica que passa a ser moldada conforme sua evolução. Reduz as incertezas e fornece estruturas de incentivos para os municípios servindo como guia para a interação que definem e limitam as escolhas da região (NORTH, 1990).

Zacarelli (2004) destaca que as instituições devem incluir "outras características relacionadas à 
Indicadores de desenvolvimento sustentáveis: uma análise comparativa das instituições formadas por agrupamentos territoriais de Santa Catarina Brasil

tecnologia, assim como a competitividade, sustentabilidade ambiental e cultural, qualidade de vida e sinergia, como resultado de relações sistêmicas". Já Porter (1999) define como "agrupamento geograficamente concentrado correlatas numa determinada área, vinculadas por elementos comuns e complementares". Nas palavras de Schmitz (1999), "as instituições conferem vantagens competitivas às empresas e às regiões que os integram, capacitando-as a atuar e competir globalmente".

Nesse sentido, as instituições passam a fornecer uma estrutura para a formação e interação social, econômica e política. North (1990) utiliza uma metáfora onde as instituições, agrupamentos territoriais, seriam as regras e as organizações, os municípios, seriam os jogadores, dessa forma, se o objetivo é definir como o jogo é jogado, o objetivo da equipe passa a ser ganhar o jogo. Para North (1990), "eles são grupos de indivíduos ligados por um objetivo comum de alcançar objetivos".

As instituições formadas por agrupamentos territoriais buscam promover um objetivo em comum para se tornar sustentável, embora elas mesclem a formação abstrata de uma estrutura, desenvolvem práticas políticas, econômicas e sociais como, "restrições informais (sanções, tabus, costumes, tradições e códigos de conduta) e as regras formais (constituições, leis, direitos de propriedade)" (NORTH, 1991). O economista argumenta que os papéis das instituições na sociedade reduzem as incertezas estabelecendo uma estrutura estável, muitas vezes não eficiente e não sustentável (NORTH, 1990).

Entretanto, elas evoluem alternando constantemente e apesar de exporem regras formais, elas podem mudar do dia para o outro devido às decisões políticas ou judiciais, já as restrições informais, estão enraizadas nos códigos de conduta sendo muito difícil sua modificação, ou seja, promovem a ordem e reduzem incertezas nas trocas, isto é, são constrangimentos humanamente concebidos que estruturam a interação política, econômica e social (NORTH, 1990). Dessa forma, as instituições buscam mecanismos estratégicos para fornecer subsídios para o crescimento e desenvolvimento dos municípios de forma sustentável.

O desenvolvimento de determinado agrupamento territorial é uma tarefa conjunta das organizações privadas e públicas através da articulação dos esforços, do planejamento e da definição concentrada de estratégia. North (1990) aponta que as instituições foram criadas ao longo da história para promover ordem e reduzir a incertezas nas trocas, elas evoluíram de forma incremental ligando o passado com o presente e o futuro, isto é, proporcionam a estrutura de incentivos de uma economia e quando ela se desenvolve molda a direção da mudança econômica para o crescimento ou declínio.

Nesse sentido, as instituições buscam promover o desenvolvimento sustentável acerca de um conceito sistêmico. Traduzem e modelam o desenvolvimento global para incorporar aspectos de um sistema de consumo em massa em que sua estrutura não visa apenas à interação e o crescimento econômico. Hodgson (2006) descreve bem o papel das instituições "[...] como sistemas de regras sociais estabelecidas e prevalecentes que estruturam as interações sociais". Dessa forma, as instituições formadas pelos agrupamentos territoriais buscam através de iniciativas e interação social formas de se desenvolverem regionalmente sustentável por meio de uma integração institucional.

Essas interações sociais devem remeter não apenas ao crescimento, visto que ele remete quase 
Indicadores de desenvolvimento sustentáveis: uma análise comparativa das instituições formadas por agrupamentos territoriais de Santa Catarina Brasil

que exclusivamente a esfera econômica, excluído aspectos essenciais como sociocultural e ambiental (FILLIPIM et al., 2005). As instituições devem ter como objetivo, ir além da mera manipulação de riqueza material, porém o crescimento é uma condição necessária, mas não o suficiente para uma qualidade de vida, ou seja, o crescimento gera desenvolvimento, quando limitado em aspectos econômicos provoca danos ao ambiente, e tende aumentar a disparidade social da região, portanto, não sendo sustentável (SACHS, 2004).

Nesse contexto, as instituições devem promover ações que envolvam interação políticas, econômicas e sociais, visto que para atingir o ápice da sustentabilidade ainda devem englobar aspectos territoriais, ecológicos, ambientais, políticas nacionais e internacionais. Todos esses aspectos refletem uma leitura do desenvolvimento das instituições dentro de uma proposta alternativa à ordem econômica. Na visão de Veblen (1965) "a situação de hoje modela as instituições de amanhã mediante um processo seletivo e coercitivo", ou seja, as instituições passam a seguir padrões determinados pela sociedade.

\section{O Desenvolvimento Sustentável}

Etimologicamente o termo sustentável tem origem latim sustentare, qual seu significado está em sustentar ou conservar, este conceito está diretamente relacionado a uma atitude ou estratégia ecologicamente correta no âmbito social e econômico com uma diversificação cultural. Já o desenvolvimento sustentável busca ser capaz de suprir as necessidades da geração atual, sem comprometer a capacidade de atender as necessidades das futuras gerações (SACHS, 2004).

Nesse sentido, o desenvolvimento sustentável das instituições formadas pelos agrupamentos territoriais busca o desenvolvimento economicamente sustentável, em um pensamento acerca da verdadeira metamorfose do modelo civilizatório atual (SACHS, 2004). Desse modo, "as economias não se desenvolvem apenas porque elas existem. O desenvolvimento econômico tem sido uma exceção histórica e não a regra" Recupero (2002). Os agrupamentos territoriais são apenas uma das muitas instituições que influenciam no processo de desenvolvimento.

Outro ponto relevante está no modelo de desenvolvimento econômico que afirmou na era contemporânea e que está relacionado aos extremos do progresso tecnológico e bem-estar de alguns setores limitados da sociedade, isto é, na medida em que o objetivo do desenvolvimento econômico é somente a economia torna-se um modelo de autodesenvolvimento (MARTINS, 2008). Nesse sentido, a sustentabilidade será alcançada quando em termos de valorização, olharmos para o capital humano, seus costumes e saberes, ficando evidente uma visão holística da história e dos problemas da sociedade para além do pensamento apenas da gestão dos recursos naturais (JACOBI, 1999).

Sachs (1993) descreve que para ser sustentável, torna-se necessário ter uma visão dos problemas sociais e não focar apenas nos problemas dos recursos ambientais, mas sim em um pensamento profundo das mudanças do modo em que a civilização atual. Para tanto, o economista apresenta oito dimensões do ecodesenvolvimento explicadas na Tabela 1 e que podem ser planejadas quando se pensa em sustentabilidade no desenvolvimento regional (SACHS, 1993). 
Indicadores de desenvolvimento sustentáveis: uma análise comparativa das instituições formadas por agrupamentos territoriais de Santa Catarina Brasil

Tabela 1: Oito dimensões do desenvolvimento sustentável descrita por Sachs

\begin{tabular}{|l|l|}
\hline Social & $\begin{array}{l}\text { Busca alcançar um patamar razoável de hegemonia social, isto é, distribuição justa da renda, emprego pleno com } \\
\text { qualidade de vida e igualdade no acesso aos recursos sociais. }\end{array}$ \\
\hline Cultural & $\begin{array}{l}\text { Refere-se às mudanças no interior da continuidade, ou seja, a capacidade de autonomia para a elaboração de um } \\
\text { projeto nacional integrado e endógeno. }\end{array}$ \\
\hline Ambiental & Trata do respeito à capacidade de autodepuração dos ecossistemas naturais. \\
\hline Territorial & $\begin{array}{l}\text { Relacionado à preservação do potencial do capital natural e produção de recursos renováveis com limitação dos } \\
\text { recursos não renováveis. }\end{array}$ \\
\hline Econômico à configuração urbana e rural, melhoria do ambiente urbano e a superação das disparidades inter- \\
regionais e o desenvolvimento ecologicamente seguro para áreas frágeis.
\end{tabular}

Fonte: Sachs (1993).

Neste artigo as oito dimensões estão representadas por quatro pilares da sustentabilidade, que podem ser definidos como dimensão sociocultural, econômica, ambiental e político-institucional. Dessa forma, a dimensão sociocultural interliga o campo da educação, saúde, cultura e habitação, a demissão econômica relaciona a economia e a renda das instituições municipais, a dimensão ambiental o meio ambiente e a dimensão político-institucional relacionam a participação social gestão pública e finanças, todas elas relacionam com base nos oito pilares descritos por Sachs (1993). Para "alcançar um desenvolvimento genuinamente sustentável e sadio, os critérios de sustentabilidade precisam ser satisfeitos em todas as dimensões pertinentes do desenvolvimento" (SACHS, 2007), ou seja, não há como desenvolver a sustentabilidade sem que todas as dimensões estejam em equilíbrio.

\section{METODOLOGIA}

A pesquisa busca por meio de uma análise documental comparar dados referentes às instituições formadas por agrupamentos territoriais, ou seja, associações municipais. Esse método se justifica, pois, o uso de documentos em pesquisa permite acrescentar a dimensão do tempo compreendendo o social, isto é, favorece a observação da evolução dos indivíduos, conceitos e conhecimentos. (CELLARD, 2008).

Segundo Helder (2006) "a técnica documental vale-se de documentos originais, que ainda não receberam tratamento analítico por nenhum autor. Já Gauthier (1984) "trata-se de um método de coleta de dados que elimina, ao menos em parte, a eventualidade de qualquer influência - presença ou intervenção do pesquisador". Pimentel (2001) destaca que seu uso na pesquisa tem o intuito de contribuir para a utilização apresentando um processo de investigação, isto é, passa a ser descrito como instrumento e meios de realização da análise de conteúdo, apontando o percurso em que as decisões foram sendo 
Indicadores de desenvolvimento sustentáveis: uma análise comparativa das instituições formadas por agrupamentos territoriais de Santa Catarina Brasil

tomadas.

Portanto, o universo da pesquisa buscou analisar os indicadores de desenvolvimento sustentável e suas relações através dos 21 agrupamentos territoriais que contemplam os 295 municípios do estado de Santa Catarina. Dessa forma, a Figura 1 demonstra onde se encontra cada instituição dentro do estado catarinense.

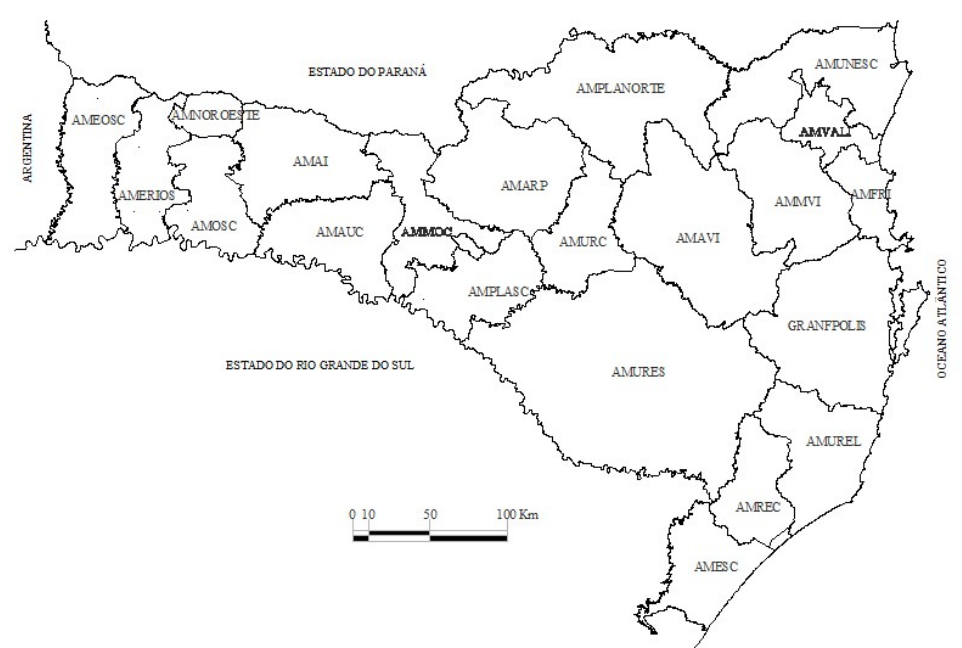

Figura 1: Divisão do estado catarinense em agrupamentos territoriais. Fonte: IBGE (2000)

Os índices municipais estão classificados de modo que o leitor possa verificar as classificações dos municípios e regiões, ou seja, quando o valor do Índice de Desenvolvimento Municipal Sustentável (IDMS) estiver maior ou igual a 0,875, será considerado uma classificação alta, maior ou igual a 0,750 e menor do que 0,875 , média alta, maior ou igual a 0,625 e menor do que 0,750 média, maior ou igual a 0,500 e menor do que 0,625 média baixa e menor do 0,500 considerada uma classificação baixa. Nesse sentido, classificaram-se as regiões que mais se desenvolveram entre 2012 e 2014 comparando o equilíbrio das dimensões do desenvolvimento sustentável. Das três regiões que encontram melhores colocadas, como das três regiões que estão em último na classificação geral dos indicadores, bem como, verificando a região que mais se desenvolveu, obtendo a maior variação de crescimento.

\section{RESULTADOS E DISCUSSÃO}

\section{Uma análise comparativa das instituições}

Em 1961 fundou-se Associação dos Municípios do Meio Oeste Catarinense (AMMOC) com o intuito de promover o desenvolvimento regional. Desde lá, outras associações foram se formando e fortalecendo. Atualmente são 21 associações que contemplam 295 municípios no estado de Santa Catarina. Nesse sentido, o estado passa a ser dividido por agrupamentos territoriais, formadas por municipalidades com características e interesses territoriais comuns, unificadas formando instituições que interligam os municípios fortalecendo o desenvolvimento regional.

As associações municipais são caracterizadas como entidades jurídicas de direito privado, sem fins lucrativos, com estatuto próprio aprovado em Assembleia Geral. Portanto, são "curiosas figuras de Direito Privado, integradas por instituições de Direito Público" (MELO, 1972). Nesse sentido, a principal 
característica desses agrupamentos territoriais, está em interligar administrativamente, economicamente e socialmente os municípios, isto é, implementar e articular o desenvolvimento, tanto com os municípios, Estado ou União. Na Tabela 2 demonstramos as 21 associações municipais e os respectivos municípios que as compõem.

Tabela 2: Associações Municipais do Estado de Santa Catarina

\begin{tabular}{|c|c|}
\hline $\begin{array}{l}\text { AMAI - Associação dos } \\
\text { Municípios do Alto Irani }\end{array}$ & $\begin{array}{l}\text { Abelardo Luz, Bom Jesus, Entre Rios, Faxinal dos Guedes, Ipuaçu, Lajeado Grande, Marema, Ouro Verde, Passos } \\
\text { Maia, Ponte Serrada, São Domingos, Vargeão, Xanxerê, Xaxim }\end{array}$ \\
\hline $\begin{array}{l}\text { AMEOSC - Associação dos } \\
\text { Municípios do Extremo Oeste de } \\
\text { Santa Catarina }\end{array}$ & $\begin{array}{l}\text { Anchieta, Bandeirante, Barra Bonita, Belmonte, Descanso, Dionísio Cerqueira, Guaraciaba, Guarujá do Sul, Iporã } \\
\text { do Oeste, Itapiranga, Mondaí, Palma Sola, Paraíso, Princesa, Santa Helena, São João do Oeste, São José do } \\
\text { Cedro, São Miguel do Oeste, Tunápolis }\end{array}$ \\
\hline $\begin{array}{l}\text { AMMOC - Associação dos } \\
\text { Municípios do Meio Oeste } \\
\text { Catarinense }\end{array}$ & $\begin{array}{l}\text { Água Doce, Capinzal, Catanduvas, Erval Velho, Herval d’Oeste, Ibicaré, Joaçaba, Lacerdópolis, Luzerna, Ouro, } \\
\text { Tangará, Treze Tílias, Vargem Bonita }\end{array}$ \\
\hline $\begin{array}{l}\text { AMPLANORTE - Associação dos } \\
\text { Municípios do Planalto Norte } \\
\text { Catarinense }\end{array}$ & $\begin{array}{l}\text { Bela Vista do Toldo, Canoinhas, Irineópolis, Itaiópolis, Mafra, Major Vieira, Monte Castelo, Papanduva, Porto } \\
\text { União, Três Barras }\end{array}$ \\
\hline $\begin{array}{l}\text { GRANFPOLIS - Associação dos } \\
\text { Municípios da Grande } \\
\text { Florianópolis }\end{array}$ & $\begin{array}{l}\text { Águas Mornas, Alfredo Wagner, Angelina, Anitápolis, Antônio Carlos, Biguaçu, Canelinha, Florianópolis, } \\
\text { Garopaba, Governador Celso Ramos, Leoberto Leal, Major Gercino, Nova Trento, Palhoça, Paulo Lopes, Rancho } \\
\text { Queimado, Santo, Amaro da Imperatriz, São Bonifácio, São João Batista, São José, São Pedro de Alcântara, } \\
\text { Tijucas }\end{array}$ \\
\hline $\begin{array}{l}\text { AMURC - Associação de } \\
\text { Municípios da Região do } \\
\text { Contestado }\end{array}$ & Curitibanos, Frei Rogério, Ponte Alta do Norte, Santa Cecília, São Cristóvão do Sul \\
\hline $\begin{array}{l}\text { AMARP - Associação dos } \\
\text { Municípios do Alto Vale do Rio } \\
\text { do Peixe }\end{array}$ & $\begin{array}{l}\text { Arroio Trinta, Caçador, Calmon, Fraiburgo, Ibiam, lomerê, Lebon Régis, Macieira, Matos Costa, Pinheiro Preto, } \\
\text { Rio das Antas, Salto Veloso, Timbó Grande, Videira }\end{array}$ \\
\hline $\begin{array}{l}\text { AMERIOS - Associação dos } \\
\text { Municípios do Entre Rios }\end{array}$ & $\begin{array}{l}\text { Bom Jesus do Oeste, Caibi, Campo Erê, Cunha Porã, Cunhataí, Flor do Sertão, Iraceminha, Maravilha, Modelo, } \\
\text { Palmitos, Riqueza, Romelândia, Saltinho, Santa Terezinha do Progresso, São Miguel da Boa Vista, Saudades, } \\
\text { Tigrinhos }\end{array}$ \\
\hline $\begin{array}{l}\text { AMMVI - Associação dos } \\
\text { Municípios do Médio Vale do } \\
\text { Itajaí }\end{array}$ & $\begin{array}{l}\text { Apiúna, Ascurra, Benedito Novo, Blumenau, Botuverá, Brusque, Doutor Pedrinho, Gaspar, Guabiruba, Indaial, } \\
\text { Pomerode, Rio dos Cedros, Rodeiom Timbó }\end{array}$ \\
\hline $\begin{array}{l}\text { AMPLASC - Associação dos } \\
\text { Municípios do Planalto Sul de } \\
\text { Santa Catarina }\end{array}$ & Abdon Batista, Brunópolis, Campos Novos, Celso Ramos, Monte, Carlo, Vargem, Zortéa \\
\hline $\begin{array}{l}\text { AMUREL - Associação dos } \\
\text { Municípios da Região de Laguna }\end{array}$ & $\begin{array}{l}\text { Armazém, Braço do Norte, Capivari de Baixo, Grão Pará, Gravatal, Imaruí, Imbituba, Jaguaruna, Laguna, Pedras } \\
\text { Grandes, Pescaria Brava, Rio Fortuna, Sangão, Santa Rosa de Lima, São Ludgero, São Martinho, Treze de Maio, } \\
\text { Tubarão }\end{array}$ \\
\hline $\begin{array}{l}\text { AMAUC - Associação dos } \\
\text { Municípios do Alto Uruguai } \\
\text { Catarinense }\end{array}$ & $\begin{array}{l}\text { Alto Bela Vista, Arabutã, Concórdia, Ipira, Ipumirim, Irani, Itá, Jaborá, Lindóia do Sul, Paial, Peritiba, Piratuba, } \\
\text { Presidente Castello Branco, Seara, Xavantina }\end{array}$ \\
\hline $\begin{array}{l}\text { AMESC - Associação dos } \\
\text { Municípios do Extremo Sul } \\
\text { Catarinense }\end{array}$ & $\begin{array}{l}\text { Araranguá, Balneário Arroio do Silva, Balneário Gaivota, Ermo, Jacinto Machado, Maracajá, Meleiro, Morro } \\
\text { Grande, Passo de Torres, Praia Grande, Santa Rosa do Sul, São João do Sul, Sombrio, Timbé do Sul, Turvo }\end{array}$ \\
\hline $\begin{array}{l}\text { AMNOROESTE - Associação dos } \\
\text { Municípios do Noroeste } \\
\text { Catarinense }\end{array}$ & Coronel Martins, Galvão, Jupiá, Novo Horizonte, São Bernardino, São Lourenço do Oeste \\
\hline $\begin{array}{l}\text { AMREC - Associação dos } \\
\text { Municípios da Região } \\
\text { Carbonífera }\end{array}$ & $\begin{array}{l}\text { Balneário Rincão, Cocal do Sul, Criciúma, Forquilhinha } \\
\text { Içara, Lauro Muller, Morro da Fumaça, Nova Veneza, Orleans, Siderópolis, Treviso, Urussanga }\end{array}$ \\
\hline $\begin{array}{l}\text { AMURES - Associação dos } \\
\text { Municípios da Região Serrana }\end{array}$ & $\begin{array}{l}\text { Anita Garibaldi, Bocaina do Sul, Bom Jardim da Serra, Bom Retiro, Campo Belo do Sul, Capão Alto, Cerro Negro, } \\
\text { Correia Pinto, Lages, Otacílio Costa, Painel, Palmeira, Ponte Alta, Rio Rufino, São Joaquim, São José do Cerrito, } \\
\text { Urubici, Urupema }\end{array}$ \\
\hline
\end{tabular}


Indicadores de desenvolvimento sustentáveis: uma análise comparativa das instituições formadas por agrupamentos territoriais de Santa Catarina Brasil

FERREIRA, A. S.

\begin{tabular}{|c|c|}
\hline $\begin{array}{l}\text { AMFRI - Associação dos } \\
\text { Municípios da Foz do Rio Itajaí }\end{array}$ & Balneário Piçarras, Bombinhas, Camboriú, Ilhota, Itajaí, Itapema, Luíz Alves, Navegantes, Penha, Porto Belo \\
\hline $\begin{array}{l}\text { AMOSC - Associação dos } \\
\text { Municípios do Oeste de Santa } \\
\text { Catarina }\end{array}$ & $\begin{array}{l}\text { Águas de Chapecó, Águas Frias, Arvoredo, Caxambu do Sul, Chapecó, Cordilheira Alta, Coronel Freitas, Formosa } \\
\text { do Sul, Guatambu, Irati, Jardinópolis, Nova Erechim, Nova Itaberaba, Pinhalzinho, Planalto Alegre, Quilombo, } \\
\text { Santiago do Sul, São Carlos, Serra Alta, Sul Brasil, União do Oeste }\end{array}$ \\
\hline $\begin{array}{l}\text { AMUNESC - Associação dos } \\
\text { Municípios do Nordeste de } \\
\text { Santa Catarina }\end{array}$ & $\begin{array}{l}\text { Araquari, Balneário Barra do Sul, Campo Alegre, Garuva, Itapoá, Joinville, Rio Negrinho, São Bento do Sul, São } \\
\text { Francisco do Sul }\end{array}$ \\
\hline $\begin{array}{l}\text { AMVALI - Associação dos } \\
\text { Municípios do Vale do Itapocú }\end{array}$ & Barra Velha, Corupá, Guaramirim, Jaraguá do Sul, Massaranduba, São João do Itaperiú, Schroeder \\
\hline $\begin{array}{l}\text { AMAVI - Associação dos } \\
\text { Municípios do Alto Vale do Itajaí }\end{array}$ & $\begin{array}{l}\text { Agrolândia, Agronômica, Atalanta, Aurora, Braço do Trombudo } \\
\text { Chapadão do Lageado, Dona Emma, Ibirama, Imbuia, Ituporanga, José Boiteux, Laurentino, Lontras, Mirim Doce, } \\
\text { Petrolândia, Pouso Redondo, Presidente Getúlio, Presidente Nereu, Rio do Campo, Rio do Oeste, Rio do Sul, } \\
\text { Salete, Santa Terezinha, Taió, Trombudo Central, Vidal Ramos, Vitor Meireles, Witmarsum }\end{array}$ \\
\hline
\end{tabular}

Fonte: FECAM (2015).

As instituições formadas pelas associações municipais no estado de Santa Catarina são novas e seu desenvolvimento é o resultado da sua evolução que passa a ser dependente de uma trajetória histórica. Elas buscam construir redes de incentivo na ordem política, econômica e social moldando-se conforme sua evolução. Nesse sentido, verificou a sustentabilidade dessas instituições e relacionar as redes de relações sustentáveis entre elas, isto é, os municípios que compõem estas instituições devem ir além da manipulação de riquezas materiais e sim promover o bem-estar e a qualidade de vida, buscando o crescimento e o desenvolvimento econômico, diminuindo a disparidade social regional, tomando assim, instituições sustentável (SACHS, 2004).

Portanto, as instituições só se tornarão sustentáveis quando o desenvolvimento for socialmente includente, politicamente descentralizado e ambientalmente prudente e economicamente sustentável durante o tempo, satisfazendo as necessidades presentes sem comprometer a capacidade das gerações futuras (RELATÓRIO DE BRUNDTLAND, 1987). As quatro dimensões que representam a realidade das instituições e que podem ser vistas como as grandes áreas do desenvolvimento sustentável, caracterizadas no campo sociocultural, econômico, ambiental e político-institucional. Para tanto, a Figura 2 demonstra o nível e a classificação do desenvolvimento municipal sustentável dos vinte e um agrupamentos territoriais do estado de Santa Catarina.

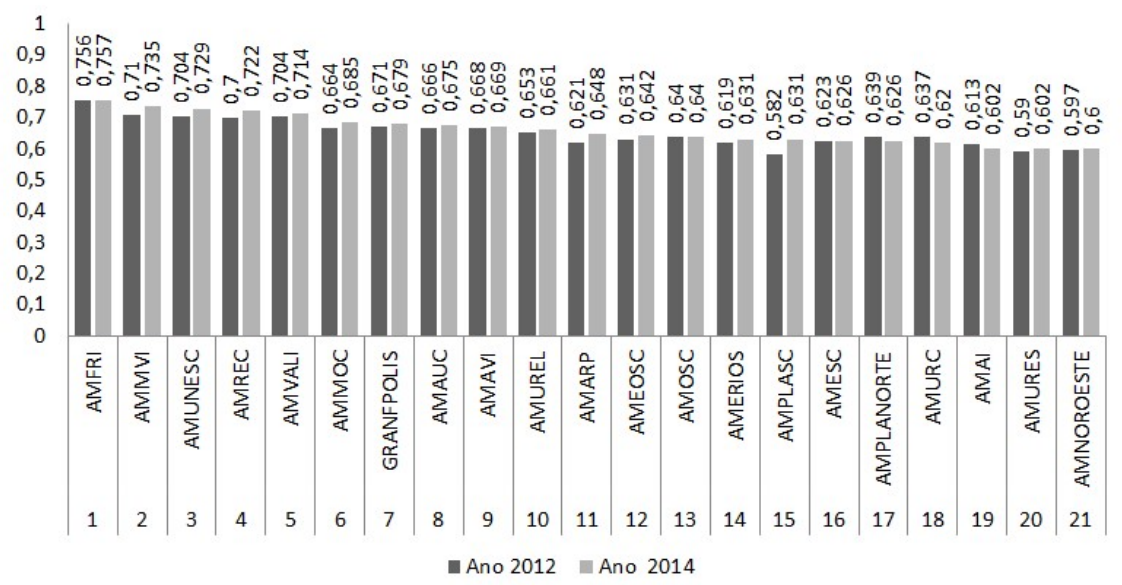

Figura 2: Indicadores de desenvolvimento municipal sustentável (IDMS) das associações municipais. Fonte: $\operatorname{FECAM}(2012 ; 2014)$. 
Indicadores de desenvolvimento sustentáveis: uma análise comparativa das instituições formadas por agrupamentos territoriais de Santa Catarina Brasil

Entre o ano de 2012 para 2014 mais de 80\% das instituições tiveram alta nos indicadores, sendo que $5 \%$ mantiveram o índice e $15 \%$ tiveram queda no índice de desenvolvimento sustentável, o que corresponde a três instituições. Esta queda nos indicadores corresponde a 1, 1\% para AMAl, 1, 3\% para AMPLANORTE e 1, 7\% para a AMURC. Já a AMPLASC foi a instituição que apresentou a maior alta de 4, 9\% no indicador geral de sustentabilidade.

As instituições que ficaram entre os cinco primeiros lugares, percebemos um baixo percentual de aumento, ou seja, a AMFRI alternou de 0,756 para 0,757 cerca de $0,1 \%$ já a AMMVI, AMUNESC aumentaram 2, 5\% e a AMREC 2, 2\% enquanto a AMVALI teve alta de $1 \%$. Já as últimas cinco instituições tiveram uma disparidade interessante, enquanto as duas últimas colocadas, AMNOROESTE teve alta de 0 , $3 \%$ e a AMURES 1, 2\% a AMAl teve baixa de 1, 1\%, AMURC 1, 7\% e a AMPLANORTE 1, 3\%. Já as últimas cinco instituições: AMAI, AMARP, AMPLASC, AMURES e AMURC registraram queda nos indicadores de desenvolvimento sustentável. A AMAI passou de 0,688 para 0,663 registrando queda de 2, 5\%, a AMARP 3, 5\%, a AMPLASC 2, 6\%, AMURES 0, 9\% enquanto a AMURC registrou a maior queda de 0, 686 em 2012 para 0, 609 em 2014 ou seja, 7, 7\%.

Por outro lado, as cinco primeiras colocadas na dimensão sociocultural variam da colocação geral no índice de sustentabilidade. A AMFRI manteve na primeira colocação na dimensão com alta de $0,9 \%$. A AMVALI passou da quinta colocação no índice geral para a segunda colocação, com uma variação positiva de 3, 3\%. Já a AMAUC saiu da oitava colocação, subindo para a terceira, mesmo demonstrando uma baixa no indicador de 1, 1\%. A AMREC manteve a mesma colocação, tendo um indicador positivo 2, 6\%. A MMVI ficou com a quinta colocação e teve a maior alta no indicador sociocultural, com cerca de 4, $3 \%$.

A AMFRI manteve com a primeira colocação com alta de $0,7 \%$, seguida da AMVALI com alta de 3, $9 \%$, sobe para a terceira colocação a mesma do índice geral com 3, 3\% de alta. A AMREC representou baixa de 0, 4\% seguida da AMUNESC que estava com 0, 74 em 2012 baixando para 0, 709 em 2014, registrando queda de 3,1\% na dimensão econômica.

Quando se verifica as últimas cinco colocadas, percebe-se que AMARP registrou queda de 4, 2\% com índices de 0,622 caindo para 0,580. A AMURC apresentou o menor índice entre as cinco, com queda de $0,6 \%$ enquanto AMURES demonstrou queda de $2,1 \%$ seguida da AMNOROESTE com 5,9\%, já a AMPLASC que encontra em $15^{\circ}$ posição no índice geral apresentou o pior índice, cerda de $12,2 \%$ de queda. A partir da $6^{\circ}$ colocação nesse indicador até a $16^{\circ}$ percebemos que apenas três instituições demonstraram alta nesse indicador, isto é, GRANFPOLIS com 2,3\%, AMUNESC com 0,3\% e a AMMOC com 0,1\%. As demais apresentaram indicadores com baixa em relação ao ano de 2012 para 2014.

Verificamos também a dimensão ambiental, composta pelos indicadores que correspondem à cobertura de saneamento básico, estrutura de gestão ambiental e preservação ambiental que indicam o percentual de domicílios atendidos direta ou indiretamente por coleta de lixo, acesso à rede geral de esgoto ou fossa séptica e rede pública de água. Bem como, a efetividade da estrutura de gestão ambiental e do conselho municipal de meio ambiente, com depósito de lixo em locais licenciados e áreas de matas e florestas naturais preservadas nas propriedades agropecuárias (SIDEMS, 2015). 
Indicadores de desenvolvimento sustentáveis: uma análise comparativa das instituições formadas por agrupamentos territoriais de Santa Catarina Brasil

FERREIRA, A. S.

Nesse indicador os resultados não são satisfatórios, todas as cinco primeiras demonstraram queda nos indicadores, AMMVI saiu de 0,824 em 2012 para 0,778 em 2014 cerca de 4,6\%, mesmo com a queda manteve-se na primeira colocação nesse indicador. A AMFRI teve queda de $0,3 \%$ enquanto a AMREC apresentou 3,1\% de queda, já a AMUNESC em 2012 estava com 0,800 caindo para 0,745 em 2014 cerca de $5,5 \%$, e a AMVALI dentre as cinco foi a que mais registrou queda nos indicadores cerca de $9,2 \%$ caindo de 0 , 814 para 0,722 . Já entre os cinco últimos colocados, AMPLASC apresentou a maior queda de 0,595 em 2012 para 0,522 em 2014, cerca de 7,3\%. A AMOSC ficou com a $18^{\circ}$ colocação com crescimento de $0,6 \%$, ou seja, passou de 0,506 para 0,512. A AMAl teve baixa de 2,9\%, seguida da AMNOROESTE, o qual, apresentou melhora de 0,428 e 2012 para 0,455 em 2014 cerca de 2,7\% de crescimento. Apesar de AMNOROESTE apresentar um indicador positivo, está muito abaixo do desejável, já que este indicador mede em uma escala de 0 a 1.

Nessa dimensão a AMURC apresentou indicador positivo com alta de 3,8\% e GRANFPOLIS 0,9\%, já a AMEOSC manteve o mesmo indicador não tendo alteração. As demais instituições tiveram uma baixa no percentual que varia de $0,1 \%$ a 4,4\%. O SIDMS (2012) descreve que a o "poder público exerce um papel fundamental na dinamização do desenvolvimento sustentável local”. Portanto as iniciativas públicas passam a constituir o principal catalisador dos processos de transformação da realidade local. Dessa forma, a dimensão político institucional passa a considerar as variáveis relacionadas à receita corrente líquida per capita, a receita própria sobre a receita corrente líquida, ao investimento público per capita, ao investimento público sobre a receita corrente líquida e a suficiência de caixa, bem como, o percentual da receita comprometida com folha de pessoal (SIDEMS, 2014), demonstramos nesse indicador que apenas a AMAI apresentou alteração crescente de $1 \%$ sendo que a AMFRI seu percentual foi mais tímido cerca de 0 , $1 \%$ crescente.

Já as demais demonstraram queda nesse indicador, correspondendo $90 \%$ das instituições, isto é, AMOSC teve queda de 1,9\%, AMUNESC 1\%, AMAUC 3,9\%, AMERIOS 4,7\%, AMEOSC 0, 7\%, AMNOROESTE 2,9\%, AMMVI 4,7\%, AMMOC 6,7\%, AMREC 2,7\%, AMPLASC 2,8\%, AMAVI 2,8\%, AMURC 4,3\%, AMUREL 3,1\%, GRANFPOLIS 2,8\%, AMARP 5,8\%, AMESC 4,4\%, AMPLANORTE, 2,7\% e a AMURES 3,0\% de queda.

\section{As instituições com o menor índice de desenvolvimento}

Em relação à Figura 1, como já foi referido anteriormente apenas três instituições tiveram um indicador negativo no índice de desenvolvimento municipal sustentável, isto é, a instituição AMPLANORTE passou de 0,639 para 0,626 com queda de 1, 3\% mantendo seu indicador com classificação de médio. Já a AMURC passou do 0,637 para 0,62 com queda de 1, 7\%, caindo de médio para médio a baixo. A AMAI passou de 0,613 para 0,602 , com queda de 1,1\%, mantendo-se dentro do nível médio baixo.

Para entender melhor a queda nos indicadores das três instituições, analisou as quatro dimensões, sociocultural, econômico, ambiental e político-institucional. Na dimensão sociocultural temos queda da AMAI em 2,5\%, AMPLANORTE em 1,4\% e a AMURC em 7,7\%. Alguns indicadores podem ter interferido para esta queda, na AMAI percebe-se um decréscimo na educação de 4, 6\% e 1, 4\% na AMPLANORTE sendo que 
Indicadores de desenvolvimento sustentáveis: uma análise comparativa das instituições formadas por agrupamentos territoriais de Santa Catarina Brasil

a AMURC teve queda de 7, 7\%. Entre as duas primeiras houve uma baixa no percentual de abandono escolar no ensino médio $25,1 \%$ na AMAI e $0,5 \%$ na AMPLANORTE e na taxa de atendimento escolar de 6 a 14 anos da rede pública e privada uma queda de $29 \%$ na AMAl e 7,8\% na AMPLANORTE.

A AMURC, além de ter queda no percentual de abandono escolar de $25 \%$ e de $19 \%$ na taxa de atendimento escolar de 6 a 14, também demonstrou uma queda de 5,3\% no IDEB da rede pública nos anos finais do 6 ao 9 ano. Para Sachs (2004), este indicador é a essência, pois reflete na formação do sujeito os quais serão promotores do desenvolvimento sustentável, isto é "a educação é essencial para o desenvolvimento, pelo valor intrínseco, na medida em que contribui para o despertar cultural, a conscientização, a compreensão dos direitos humanos" (SACHS, 2007).

Além da educação, analisaram-se os indicadores de saúde, cultura e habitação, que fazem parte da dimensão sociocultural. As três apresentam quedas nos indicadores que corresponde à saúde, sendo AMAI 6, $1 \%$, AMPLANORTE $0,1 \%$ e a AMURC com o maior índice $8,1 \%$, que representam uma queda nos recursos na saúde de $22,2 \%$, bem como, um aumento morbidade $7,9 \%$ e mortalidade $14,7 \%$. Já na habitação a AMPLANORTE e AMURC demonstram o mesmo indicador de $5 \%$ de queda. A Figura 3 demonstra o comparativo dos quatro indicadores analisados, entre o ano de 2012 e 2014.

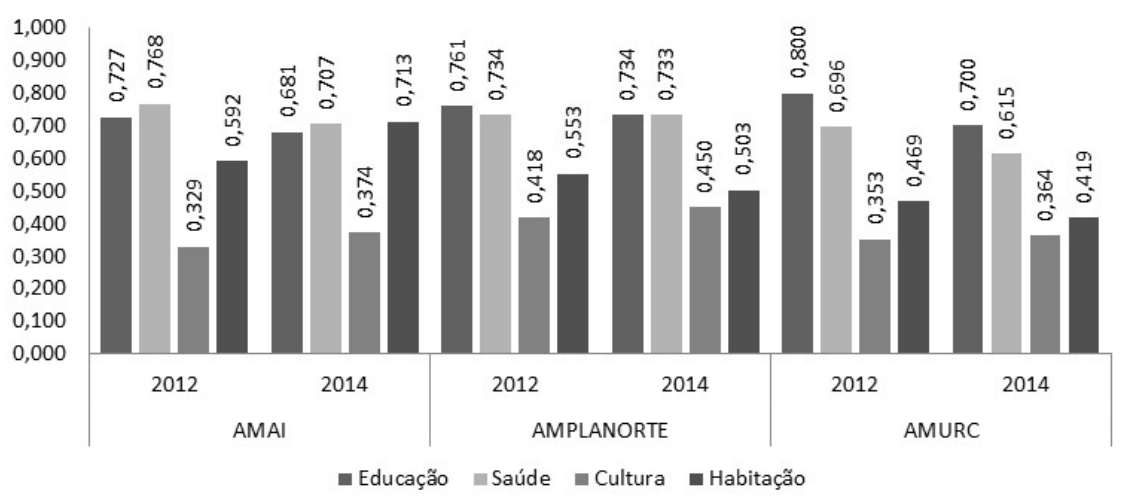

Figura 3: Demonstrativo dos indicadores da subdivisão sociocultural do ano de 2012 e 2014. Fonte: FECAM (2012; 2014)

Na dimensão econômica a AMAI apresentou queda de 3,8\% e a AMPLANORTE 6, 1\%, já a AMURC apresentou uma alta de $0,6 \%$. Nesse indicador percebeu um grande percentual de queda em indicadores semelhantes, como evolução da área liberada para construção no último triênio que foi negativo com 25, 9 \% para AMAI enquanto a AMPLANORTE apresentou 12, 4\% de queda. Outro indicador foi a evolução média do PIB no último triênio que demonstrou queda de 22, 1\% enquanto a AMAI apresentou queda de 17, 6\%.

Já a média de crescimento do Imposto Sobre Serviço no último triênio demonstrou que a AMAI demonstrou queda de 20,3\% enquanto AMPLANORTE apresentou queda de $16 \%$. A AMPLANORTE ainda apresentou queda de na evolução dos empregos formais no último triênio de 1, 5\%, redução no PIB per capita de $7,5 \%$ e redução na evolução média do valor adicionado no último triênio de $2,3 \%$. Na dimensão ambiental a AMAI apresentou uma alta de 2, 9\% enquanto a AMPLANORTE registrou queda de $0,4 \%$ e a AMURC queda de 3, 8\%. A maioria dos indicadores não obteve alteração sendo que efetividade da 
Indicadores de desenvolvimento sustentáveis: uma análise comparativa das instituições formadas por agrupamentos territoriais de Santa Catarina Brasil

estrutura de gestão ambiental a AMPLANORTE apresentou queda de $2 \%$ e AMURC $24 \%$ um índice alto quando se trata na efetividade da gestão ambiental municipal, enquanto a efetividade do conselho municipal de meio ambiente a AMPLANORTE teve uma queda os indicadores de 0.515 para 0,41 , ou seja, $10,5 \%$.

Já a dimensão política institucional apenas a AMAI apresentou índice negativo com $1 \%$ em relação ao ano de 2012 para 2014. A AMPLANORTE apresentou um índice positivo de 2, 7\% e a AMURC 4, 3\%. Na AMAl foi possível identificar alguns pontos que registraram maior alta como a finanças públicas com queda 0, 705 para 0,631, cerca de 7, 4\%, enquanto a gestão pública registrou baixa de 0,685 para 0,657 , cerca de 2, 8\%. Apenas a participação social demonstrou alta de 0, 495 para 0, 588 cerca de 9, 3\%. Os principais pontos estão identificados no investimento público per capita que demonstrou uma queda de $14 \%$ e o investimento público sobre a receita corrente líquida com baixa 7,5\%, percentual da receita comprometida com folha de pessoal com comprometimento de $13 \%$, suficiência de caixa com $7,2 \%$. Na gestão pública, o indicador onde teve maior queda está na capacidade de planejamento, onde registrou queda $11,5 \%$. Entretanto nenhuma das três instituições ficou com indicador classificado como baixo. A Figura 4 demonstra o comparativo dos indicadores sociocultural, econômico ambiental e político institucional das três instituições que ficaram com indicador com queda em 2012 em relação a 2014.

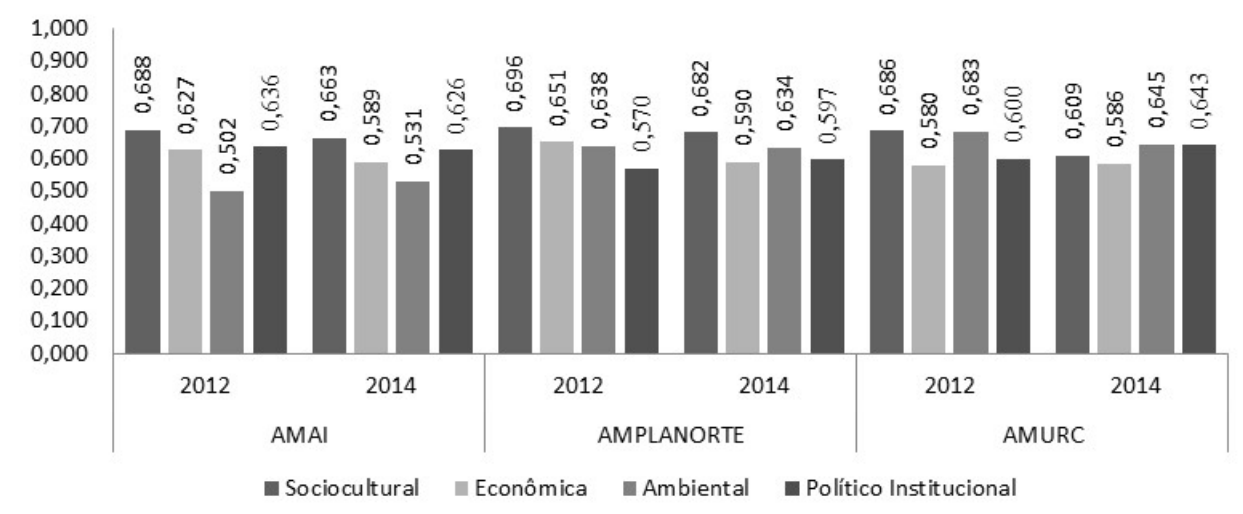

Figura 4: Indicadores sociocultural, econômico ambiental e político institucional das três instituições. Fonte: FECAM (2012 e 2014)

\section{As instituições com o melhor índice de desenvolvimento}

As instituições formadas pelos agrupamentos territoriais passam a formar redes que interligam os municípios promovendo o desenvolvimento. Nesse sentido, verificamos seus indicadores com o maior percentual de crescimento entre o ano de 2012 comparando com os indicadores de 2014. Entre as vinte e uma instituições presentes no estado de Santa Catarina a AMFRI demonstrou o maior indicador de desenvolvimento sustentável, cerca de 0,757, o que representa um crescimento de 0,1\% entre 2012 para 2014. No entanto, o indicador que corresponde à dimensão sociocultural apresentou uma alta de 0,9\%, indicador que corresponde a educação, cultura e habitação.

Já na dimensão econômica a variação foi negativa, passando de 0,760 para 0,753 , cerca de $0,7 \%$, o qual corresponde a uma queda no dinamismo econômico e na agregação de valor econômico que indica 
Indicadores de desenvolvimento sustentáveis: uma análise comparativa das instituições formadas por agrupamentos territoriais de Santa Catarina Brasil

uma variação negativa na evolução média do valor adicionado no último triênio e na média de crescimento do ISS no último triênio.

A dimensão ambiental apresentou alta de 0,3\%, isto é, passou de 0, 761 em 2012 para 0, 764 em 2014, esse aumento corresponde à melhora na estrutura de gestão ambiental com a efetividade da estrutura de gestão ambiental e do conselho municipal de meio ambiente, bem como, na preservação ambiental com a melhora no depósito de lixo em locais licenciados e o aumento de áreas de matas e florestas naturais preservadas nas propriedades agropecuárias. A dimensão política institucional teve como indicador em 2012 de 0, 756 e passou em 2014 para 0, 755 uma queda de 0,1\%, tendo baixa na capacidade de investimento público per capita e público sobre a receita corrente líquida, bem como, na saúde financeira com baixa na suficiência de caixa que passou de 1 para 0, 900. Já na gestão pública a queda foi nos indicadores da capacidade de planejamento na existência de planos de desenvolvimento setoriais, como na qualidade do quadro funcional com o percentual de servidores com curso superior. $\mathrm{Na}$ participação social, a queda está na gestão democrática com a pouca efetividade dos conselhos municipais paritários.

Analisou os municípios que compõem a AMFRI, e nesse ponto da análise percebeu-se uma queda nos indicadores dos municípios de Itapema que encontrava em 2012 em $1^{\circ}$ lugar sendo que em 2014 passou para $4^{\circ}$. Já Balneária Piçarra teve queda de dez posições, Porto Belo sessenta e sete posições, Luís Alves setenta e seis posições passando da $45^{\circ}$ posição para $121^{\circ}$ posição. Entretanto, Camboriú teve uma alteração de setenta posições, subindo da $98^{\circ}$ para $28^{\circ}$, os outros municípios que compõem a AMFRI não tiveram grandes alterações. Bombinhas caíram uma posição, Itapema três posições e Penha cinco posições, já Navegantes subiu nove e llhota subiu sete posições. Na Tabela 3 é possível verificar as alterações nos indicadores de 2012 para 2014 dos municípios que compõem a AMFRI.

Tabela 3: Classificação no IDMS dos municípios que compõem a ANFRI

\begin{tabular}{|c|c|c|c|c|c|}
\hline \multicolumn{3}{|c|}{ Ano de 2012} & \multicolumn{3}{|c|}{ Ano de 2014} \\
\hline Colocação & Município & Indicador & Colocação & Município & Indicador \\
\hline $1^{\circ}$ & Itapema & 0,792 & 20 & Itajaí & 0,817 \\
\hline $4^{\circ}$ & Itajaí & 0,787 & 40 & Itapema & 0,803 \\
\hline 50 & Bombinhas & 0,779 & 60 & Bombinhas & 0,797 \\
\hline $17^{\circ}$ & Navegantes & 0,745 & 80 & Navegantes & 0,792 \\
\hline $23 ㅇ$ & Balneário Piçarras & 0,736 & 280 & Camboriú & 0,744 \\
\hline 270 & Porto Belo & 0,730 & $33 \circ$ & Balneário Piçarras & 0,738 \\
\hline $33^{\circ}$ & Penha & 0,725 & 380 & Penha & 0,731 \\
\hline 450 & Luís Alves & 0,714 & $94^{\circ}$ & Porto Belo & 0,695 \\
\hline 980 & Camboriú & 0,675 & $121^{\circ}$ & Luís Alves & 0,677 \\
\hline 2050 & Ilhota & 0,617 & $198^{\circ}$ & Ilhota & 0,629 \\
\hline
\end{tabular}

Fonte: FECAM (2012; 2014). 
Indicadores de desenvolvimento sustentáveis: uma análise comparativa das instituições formadas por agrupamentos territoriais de Santa Catarina Brasil

A apesar das grandes quedas nos indicadores os municípios que compões a AMFRI mantiveram $40 \%$ com indicador médio alto entre 0,817 a 0, 792 e $60 \%$ com o indicador médio entre 0,744 a 0, 629. No geral, esta condição manteve a AMFRI como uma das regiões que mais promovem o desenvolvimento sustentável no estado Catarinense. Quando analisado os resultados da AMNOROESTE que em 2014 encontra-se em última posição dentre a vinte e uma instituições, percebe-se um baixo crescimento nos indicadores, com cerca de 0,3\%, em 2012 o indicador era de 0, 597, passando para 0, 600 no ano de 2014, mantendo se na classificação de médio baixo.

Quanto verificado a dimensões da sustentabilidade a AMNOROESTE aparece com queda de 4,9\% no indicador sociocultural, isto é, o indicador educação foi o que mais teve baixa, principalmente na qualidade da educação, com baixa no IDEB da rede pública nos anos iniciais de 10 ao 50 ano, nos anos finais de 60 ao 9a ano, aumentando o percentual de abandono escolar do 60 ao 9 을 ano e do ensino médio. Já na cobertura da população em idade escolar onde a variável é taxa de atendimento escolar de 6 a 14 anos na rede pública e privada teve a maior alteração, caindo de 0, 865 em 2012 para 0, 668 em 2014, registrando uma queda nesse indicador de $19,7 \%$. Na saúde também registrou baixa nos indicadores de $5 \%$, esta baixa se deu em virtude da diminuição dos recursos na saúde, morbidade, fatores de risco e proteção e mortalidade. Na cultura a baixa foi iniciativa da sociedade, infraestrutura cultural e nos recursos investidos na cultura. $\mathrm{O}$ indicador que corresponde à estrutura de gestão para políticas habitacionais e qualidade habitacional manteve-se em alta com uma variação de 10,4\%.

A dimensão econômica registrou uma alta nos indicadores de 5,9\%, essa expressiva alta se deu principalmente pela agregação de valor econômico que corresponde à evolução média do valor adicionado no último triênio e média de crescimento do ISS no último triênio, ou seja, um aumento de $14,4 \%$. Ressaltamos que o nível de renda em 2012 foi de 0, 412 e alternando em 2014 para 0, 417 sendo considerado como um indicador baixo. A dimensão ambiental da AMNOROESTE é considerada uma das mais baixas dentre todas, no indicador cobertura de saneamento básico o índice é de 0, 378 ficando com baixo indicador o percentual de domicílios atendidos por rede pública de água e o percentual de domicílios com acesso à rede geral de esgoto ou fossa séptica. Já a estrutura de gestão ambiental que corresponde à efetividade da estrutura de gestão ambiental e do conselho municipal de meio ambiente o indicador que em 2012 era de 0,246 passou para 0,167 . Outro ponto relevante que demonstrou baixa foi às poucas áreas de matas e florestas naturais preservadas nas propriedades agropecuárias, que manteve seu indicador em 0, 482 considerado baixo.

Na dimensão política institucional a AMNOROESTE manteve com alta na gestão pública onde seu indicador atingiu os 0,725 e na participação social que saiu do 0, 459 para 0,600, com aumento na gestão democrática, participação eleitoral, e um expressivo aumento no percentual de mulheres vereadoras que em 2012 estava em 0, 056 passando em 2014 para 0, 444. Apenas na subdivisão finanças públicas o indicador foi negativo, com queda de 5,7\%, ou seja, relativamente ligada à capacidade de investimento público per capita e de investimento público sobre a receita corrente líquida, bem como, na saúde financeira que passou de 0, 903 para 0,810 no qual corresponde a suficiência de caixa e ao percentual da 
Indicadores de desenvolvimento sustentáveis: uma análise comparativa das instituições formadas por agrupamentos territoriais de Santa Catarina Brasil

receita comprometida com folha de pessoal.

Por estes indicadores serem uma média dos municípios que compõem a AMNOROESTE pode explicar a classificação dos municípios dentro do estado, ou seja, o município de São Lourenço do Oeste subiu vinte e uma posições, Galvão vinte e sete, Novo Horizonte nove e Jupiá trinta e sete posições sendo que São Bernardino caiu vinte e nove posições e Coronel Martins caiu cinquenta e quatro posições conforme demonstra na Tabela 4.

Tabela 4: Classificação no IDMS dos municípios que compõem a ANFRI

\begin{tabular}{llllll}
\hline Ano de 2012 & & \multicolumn{5}{c}{ Ano de 2014 } \\
\hline Colocação & Município & Indicador & Colocação & Município & Indicador \\
\hline $124^{\circ}$ & São Lourenço do Oeste & 0,659 & $103^{\circ}$ & São Lourenço do Oeste & 0,688 \\
226 ( & Coronel Martins & 0,600 & $231^{\circ}$ & Galvão & 0,607 \\
$245^{\circ}$ & Novo Horizonte & 0,589 & $232^{\circ}$ & Jupiá & 0,607 \\
$246^{\circ}$ & São Bernardino & 0,589 & $236^{\circ}$ & Novo Horizonte & 0,605 \\
$258^{\circ}$ & Galvão & 0,579 & $275^{\circ}$ & São Bernardino & 0,550 \\
2690 & Jupiá & 0,563 & $280^{\circ}$ & Coronel Martins & 0,542 \\
\hline
\end{tabular}

Fonte: FECAM $(2012 ; 2014)$

Apesar da AMNOROESTE estar em último colocado no índice de desenvolvimento sustentável do estado de Santa Catarina, nenhum dos seis municípios que a compõem estão entre os dez com o índice mais baixo do estado. Entre as vinte e uma instituições que dividem o estado, AMPLASC foi a que mais apresentou crescimento nos indicadores de desenvolvimento sustentável com 4, 9\%, ou seja, os municípios que compõem a AMPLASC tiveram um expressivo crescimento nos indicadores. Campos Novos subiu setenta e seis posições, Abdon Batista cento e catorze, Monte Carlo noventa e cinco, Celso Ramos sessenta e duas, Brunópolis quarenta e oito e Vargem duas, sendo que Zortéa caiu cem posições.

Notável é que o município de Vargem estava em 2012 entre os cinco com o menor indicador e quatro dos sete municípios estavam entre os últimos quinze. No entanto, em 2014 apenas o município de Vargem manteve-se entre os seis últimos do estado. A Tabela 5 demonstra a classificação dos municípios que compõem a AMPLASC e um comparativo entre os indicadores de 2012 para 2014.

Tabela 5: Classificação no IDMS dos municípios que compõem a AMPLASC

\begin{tabular}{|c|c|c|c|c|c|}
\hline \multicolumn{3}{|c|}{ Ano de 2012} & \multicolumn{3}{|c|}{ Ano de 2014} \\
\hline Colocação & Município & Indicador & Colocação & Município & Indicador \\
\hline 63 & Zortéa & 0,699 & 630 & Campos Novos & 0,715 \\
\hline $139^{\circ}$ & Campos Novos & 0,653 & 1110 & Abdon Batista & 0,681 \\
\hline $225^{\circ}$ & Abdon Batista & 0,602 & $163^{\circ}$ & Zortéa & 0,653 \\
\hline 280 & Monte Carlo & 0,551 & $185^{\circ}$ & Monte Carlo & 0,639 \\
\hline $283^{\circ}$ & Celso Ramos & 0,540 & 2210 & Celso Ramos & 0,617 \\
\hline
\end{tabular}


Indicadores de desenvolvimento sustentáveis: uma análise comparativa das instituições formadas por agrupamentos territoriais de Santa Catarina Brasil

$\begin{array}{llllll}2860 & \text { Brunópolis } & 0,534 & 2389 & \text { Brunópolis } & 0,601 \\ 2910 & \text { Vargem } & 0,493 & 2890 & \text { Vargem } & 0,514\end{array}$

Fonte: FECAM $(2012 ; 2014)$

Apesar da AMPLASC registra maior alta nos indicadores de sustentabilidade, quanto verificamos a dimensão sociocultural percebemos um resultado negativo, ou seja, passou de 0,666 para 0, 640 cerca de 2, 6\% de queda, permanecendo classificado com um indicador médio esta queda demonstrou uma baixa nas subdimensões, educação e saúde enquanto cultura, apenas o indicador habitação manteve com alta 8\% em relação ao ano de 2012.

Já na dimensão econômica a AMPLASC registrou a maior alta 12,2\%, essa alteração se dá pela agregação de valor econômico tendo como suas variáveis a evolução média do valor adicionado no último triênio que passou de 0,604 para 0,868 e a média de crescimento do ISS no último triênio, que passou de 0, 494 para 0, 888 tendo este indicador um aumento de $39 \%$ o que justifica a alta na dimensão econômica. Na dimensão ambiental AMPLASC demonstrou uma grande alta de 7, 3\% principalmente na estrutura de gestão ambiental e na preservação ambiental com depósito de lixo em locais licenciados e o aumento de áreas de matas e florestas naturais preservadas nas propriedades agropecuárias.

A dimensão política institucional a AMPLASC encontra-se entre as 10 com melhores indicadores, tendo uma alta em relação ao ano de 2012 de 2, 8\%, aumentando seus indicadores na capacidade de arrecadação e investimento que correspondem à receita corrente líquida per capita, receita própria sobre a receita corrente líquida, investimento público per capita e ao investimento público sobre a receita corrente líquida dos municípios que a compõem. Porém com baixa na saúde financeira onde a suficiência de caixa e o percentual da receita comprometida com folha de pessoal caíram de 0, 915 para 0, 751 .

\section{CONCLUSÕES}

A pesquisa teve como objetivo analisar os indicadores demonstrando quais pontos devem ser fortalecidos, bem como, comparar os pontos positivos e negativos gerando caminhos alternativos para o desenvolvimento sustentável das instituições formadas por agrupamentos territoriais do estado catarinense.

Dessa forma, evidenciou que as instituições vão além da mera manipulação de riqueza, buscando um crescimento que possa gerar um desenvolvimento sustentável, não apenas limitado nos aspectos econômicos, mas sim no meio social, político e ambiental conforme descreve Sachs, (2004). Percebeu um crescimento nos percentuais na dimensão sociocultural, política e principalmente na dimensão ambiental. Outro ponto relevante foi que as dez primeiras instituições tiveram uma variação positiva de 2012 para o ano 2014.

No entanto, evidenciou uma evolução positiva nas últimas duas instituições e uma involução nas entre as instituições da AMAI, AMURC e AMPLANORTE. Outro ponto relevante demonstrado foi o grande crescimento na AMPLASC, o qual teve o maior indicador dentre todas as vinte e uma instituições 
Indicadores de desenvolvimento sustentáveis: uma análise comparativa das instituições formadas por agrupamentos territoriais de Santa Catarina Brasil

analisadas. A pesquisa demonstrou que está direcionado em ações, tais como educação, cultura e habitação, bem como a ampliação de ações ambientais como depósito de lixo em locais licenciados e áreas de matas e florestas naturais preservadas nas propriedades agropecuárias.

Nesse sentido, o estudo traz como contribuições aspectos comportamentais das instituições, tais como a evolução dos indicadores e em quais aspectos da sustentabilidade os municípios vêm investindo empregando ações sustentáveis. O estudo está limitado a uma análise documental, como recomendações para próximos estudos seria interessante ter um foco mais aprofundado nas instituições e nos municípios que a compõem, verificando quais os municípios que mais se desenvolveram e quais as ações que eles vêm incorporando no decorrer dos anos.

\section{REFERÊNCIAS}

BERNARDES, C.. Teoria geral da administração: a análise integrada das organizações. São Paulo: Atlas, 1993.

CELLARD, A.. A pesquisa qualitativa: enfoques epistemológicos e metodológicos. Petrópolis: Vozes, 2008.

FECAM - FEDERAÇÃO CATARINENSE DE MUNICÍPIOS. Sistema de Indicadores de Desenvolvimento Municipal Sustentável: Florianópolis, FECAM, 2014.

FERREIRA, A. B. H.. Dicionário Aurélio ilustrado. Curitiba: Positivo, 2010.

FILLIPIM, E. S.; ROSSETTO, R. C.; HERMES, F. M. F.. A gestão do desenvolvimento Regional: análise de uma experiência no Meio - Oeste Catarinense. Cadernos EBAPE.BR, v.3, n2, p.2-13, 2005.

HELDER, R. R.. Como fazer análise documental. Porto: Universidade de Algarve, 2006.

HODGSON, G. M.. What are Institutions?. Journal of Economic Issues, v.40, n.1, p.1-25, 2006.

JACOBI, P. R.. Meio Ambiente e Sustentabilidade. In: CEPAM. $\mathbf{O}$ município no século $\mathbf{X X I}$ : cenários e perspectivas. São Paulo: CEPAM, 1999.

MARTINS, J. S.. A política do Brasil lúmpen e místico. São Paulo: Contexto, 2011.

MELO, O. F.. O Planejamento a nível microrregional: a experiência do Estado de Santa Catarina. SEPLAN, 1972.

NORTH, C. D.. Institutions, institutional change and economic performance. Cambridge: Cambridge University Press, 1990.

NORTH, C. D.. Economic performance through time. The American Economic Review, 1994
NORTH, C. D.. Institutions. The Journal of Economic Perspectives, v.5, n.1, p.97-112, 1994.

PIMENTEL, A.. O método da análise documental: seu uso numa pesquisa histórica. Pittsburgh, v.84, n.3, p.359-368. 2011.

PORTER, M. E.. Competição. 2 ed. Rio de Janeiro: Campus, 1999.

RECUPERO, R.. How can the Impovirishment of the Poorest Countries B Stopped? Tokyo: United Nations University, 2002.

RIBEIRO, M. A.; FRANCO, R. M.; CORDEIRO, R. C.. Desenvolvimento e meio ambiente no Brasil: a contribuição de Ignacy Sachs. Florianópolis: Palotti/APED, 1998.

SACHS, I.. Eco desenvolvimento: crescer sem destruir. São Paulo: Vértice, 1986.

SACHS, I.. Desenvolvimento includente sustentável. São Paulo: Garamod, 2004.

SACHS, I.. Desenvolvimento: Includente, sustentável, sustentado. Rio de Janeiro: Garamond, 2008.

SCHMITZ, H.. Responding to the Challenges of Globalization: local and Regional Initiatives to Promote Quality Employment. Bologna: University of Sussex, 1999.

VEBLEN, T. B.. A Teoria da Classe Ociosa: um estudo econômico das instituições. São Paulo: Livraria Pioneira, 1965.

ZACARELLI, S. B.. Estratégia e Sucesso nas Empresas. 4 ed. São Paulo: Saraiva, 2004. 